\title{
On the Phonology and Semantics of Deaccentuation
}

\author{
Naomi Tachikawa Shapiro and Arto Anttila \\ University of Washington and Stanford University
}

\section{Introduction}

The deaccentuation of given and/or repeated elements is attested in many dialects of English. The following examples come from the first inaugurals of two former U.S. presidents. Accented items appear in SMALL CAPS and deaccented items are underlined.
a. You meet heroes across a COUNTER, and they're on both SIDES of that counter.
b. We will build our defenses beyond CHALLENGE, lest weakness INVITE challenge.

(Ronald Reagan 1981)

(George W. Bush 2001)

The metrical grids in (2) are drawn from the annotated dataset described in Anttila et al. 2020. The grids convey the prosodic patterns perceived by one native speaker of English. Column height corresponds to the degree of perceived prominence. The transcriptions show that the second occurrence of a word is perceived as deaccented (COUNTER...counter, CHALLENGE...challenge) and the closest content word preceding the deaccented word is perceived as accented (SIDES, INVITE). This accentuation appears directly tied to deaccentuation.

a.

$\begin{array}{rrr}x & x & x \\ x & x & x\end{array}$
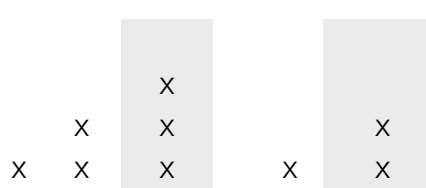

You meet heroes across a COUNTER, and they're on both SIDES of that counter .

b.

\begin{tabular}{cccccccc|c|c} 
& & & & $x$ & & & \\
& & $x$ & & $x$ & & & $x$ & \\
$x$ & $x$ & $x$ & $x$ & & $x$ & $x$ & $x$ \\
$x$ & $x$ & $x$ & $x$ & $x$ & $x$ & $x$ & $x$
\end{tabular}

We will build our defenses beyond challenge, lest weakness INVITE challenge .

Why does deaccentuation happen? One hypothesis is based on meaning: DEACCENT GiVEN states that deaccentuation targets expressions with given, entailed, coreferential, or contextually accessible meanings (Schwarzschild 1999, Arnold \& Watson 2015, Rochemont 2016, Klassen \& Wagner 2017). An alternative hypothesis is based on form: DEACCENT REPEATED holds that deaccentuation targets the second of two segmentally identical strings. This is sometimes called the WiLliams EFFECT or the ANTI-EPISTROPHE CONSTRAINT (Williams 1997, Artstein 2004, Wagner \& McCurdy 2010, Wagner 2012, 2020).

\footnotetext{
* Both authors contributed equally to this paper. The data collection and annotation were supported by the Office of the Vice-Provost for Undergraduate Education (VPUE) and by the Roberta Bowman Denning Initiative Committee at Stanford University as part of the project Prose Rhythm and Linguistic Theory. We thank the AMP 2020 audience for helpful comments and Claire Anttila, Joan Bresnan, Will Clapp, Edward Flemming, Vivienne Fong, Michael Kenstowicz, Will Leben, Rob Squizzero, and Michael Wagner for their input. We are responsible for any errors.
} 
Neither hypothesis is entirely satisfactory as the following examples show. Deaccent Given fails in (3). In (3a), both instances of six are new information: The first refers to a day, while the second refers to a year. In (3b), /tænik/ has no meaning at all.

a. Early in the morning of April twenty-SIX in nineteen EIGHTY-six

(Ira Flatow, NPR Science Friday, March 1, 2019)

b. Greek divers have found the wreck of the British liner BriTANNIC, sister ship of the Titanic.

(Ladd 1996:178)

Deaccent Repeated fails in (4), where the deaccented words have no phonologically identical antecedents.

a. Has John read Slaughterhouse-Five? No, John doesn't READ books.

(Ladd 1980:52)

b. Harry wants a VW, but his wife would prefer an AMERICAN car.

(Ladd 1980:52)

Finally, both hypotheses fail in (5):

a. A: John's mother voted for Bill.

B: No, she voted for JOHN.

(Schwarzschild 1999:142)

b. to ensure happiness and liberty for ourselves, our CHILDREN 1 , and our CHILDREN 2 's $\underline{\text { children }}_{3}$ (Ronald Reagan 1981)

In (5a), the second occurrence of John is both given and repeated, but not deaccented. In (5b), Deaccent Given predicts that CHILDREN 2 should be deaccented because it is given and children 3 should be accented because it is new, but we find the exact opposite. Likewise, Deaccent Repeated predicts that CHILDREN2 should be deaccented, which is not the case. CHILDREN 2 is both coreferential with and segmentally identical to CHILDREN 1 , so it should be deaccented on both counts, but in fact it carries nuclear stress. Finally, note that both hypotheses only account for deaccentuation. Neither addresses the concomitant accentuation of the closest content word.

Despite these shortcomings, it is unlikely that Deaccent Given and Deaccent Repeated are completely wrong. In this paper, we reformulate Deaccent Repeated as an Optimality Theoretic constraint and provide statistical evidence for it. Our proposal is summarized in (6):
a. A stress peak on a word with a segmentally identical copy in the left context is avoided.
*April twenty-six in nineteen eighty-SIX (*six...SIX)
b. Violations are repaired by minimally retracting the stress peak.
April twenty-six in nineteen EIGHTY-six
c. All words exhibit repetition-driven destressing, not just referring expressions.

The remainder of the paper is structured as follows: Section 2 outlines a phonological analysis of the key facts in simple categorical terms. Section 3 quantifies deaccentuation and presents statistical evidence for Deaccent Repeated, drawing on annotated data from Anttila et al. 2020. Section 4 concludes the paper.

\section{A phonological analysis of deaccentuation}

2.1 Deaccentuation as stress retraction Deaccentuation means that sentential prominence is absent where one would in some sense expect it. This raises two questions: What is sentential prominence and what is expected prominence? To get started, we must make a basic representational choice between the METRICAL view, which takes sentential prominences to be stresses, and the TONAL view, which takes them to be pitch accents. The literature is vast and controversial; see Gussenhoven 2011 for a helpful summary. In this short paper, we assume the metrical view, but see, for example, Liberman 1975, Liberman \& Prince 1977, Prince 1983, Hayes 1995, Ladd 1980, 1996, and Truckenbrodt 2016 for empirical justification. To the extent our metrical analysis of deaccentuation is successful, it can be read as an extended empirical argument for the metrical view of sentential prominence.

Stress has two well-known general properties. First, stress is CULMINATIVE: Each word and phrase has a 
single strongest syllable bearing the main stress. Second, stress is HIERARCHICAL: There can be multiple degrees of stress, as suggested by the traditional descriptive terms primary stress, secondary stress, tertiary stress, et cetera (Gussenhoven 2004:19-22). A key advantage of adopting the stress-based view is that it allows us to draw upon existing analyses of English phrasal stress (e.g., Chomsky \& Halle $1968=S P E$, Liberman \& Prince 1977, Cinque 1993). These analyses derive what is sometimes called a NORMAL STRESS CONTOUR that reflects the syntactic and phonological structure of the sentence, abstracting away from the effects of discourse. The normal stress contour provides an interesting baseline that reflects our structural expectations regarding the relative prominence of words. The claim defended here is that it is precisely such expectations that are flouted in deaccentuation. We thus define deaccentuation with respect to a word's expected and realized stress:

Deaccentuation: To be deaccented means to be perceived with less stress than expected.

Consider the example in (8), adapted from Ladd (1996:175). The grid shows the sentence's expected stress contour, as computed by MetricalTree (Anttila et al. 2020), ${ }^{1}$ a Python implementation of Liberman and Prince's (1977) phrasal stress algorithm, which builds on the Nuclear Stress Rule and Compound Stress Rule from $S P E$. In both clauses, primary stress is predicted to fall on whisky.

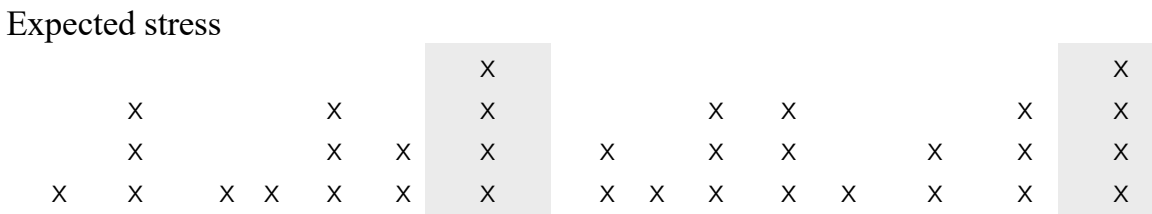

*I brought her a bottle of WHISKY . But it turns out she doesn't like WHISKY .

The stress contour in (8) is dispreferred by native speakers. Instead, the preferred contour retracts the second primary stress to the word like. Ladd's discussion suggests the contour in (9), which involves simultaneously deaccenting whisky and accenting LIKE.

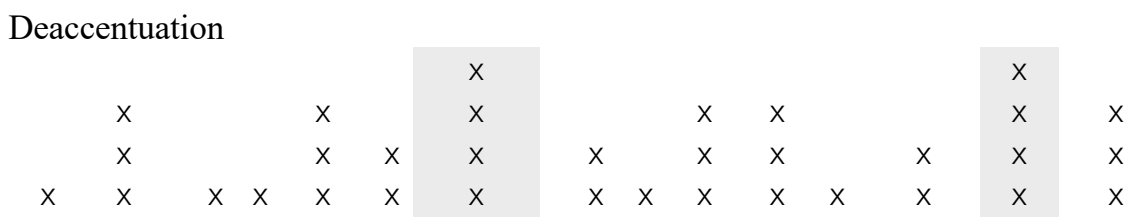

I brought her a bottle of WHISKY . But it turns out she doesn't LIKE whisky .

A preliminary phonological analysis can be stated in terms of two violable constraints. For the moment, we are only concerned with primary stress, which we refer to as a STRESS PEAK.

*STRESS-COPY Assign a violation to a stress peak on a word with a copy in the left context. RightMOST Assign a violation to every word between a stress peak and the phrase edge.

In (8), *STRESS-COPY is violated by stressing both copies of whisky. In (9), the violation is removed by retracting the second stress peak to like. RIGHTMOST guarantees that this retraction is minimal: The stress peak is retracted to the closest possible landing site, roughly corresponding to the nearest content word. ${ }^{2}$

The tableau in (11) shows how the location of stress in (9) is derived. We assume that the first clause is processed before the second and is therefore available in the context for constraint evaluation. By convention, the preceding context appears in the top left cell. Stress peaks are indicated in BOLD SMALL CAPS.

\footnotetext{
${ }^{1}$ The source code for MetricalTree is available at https://github.com/tdozat/Metrics.

${ }^{2}$ Following $S P E$, we assume that phrasal stress is restricted "as a first approximation, to the lexical categories, namely noun, adjective, verb" (Chomsky \& Halle 1968:22). The difficult problem of function word stress is addressed in Anttila et al. 2020.
} 
Deaccentuation as minimal stress retraction

\begin{tabular}{|c|c|c|}
\hline \hline I brought her a bottle of WHISKY & *STRESS-COPY & RIGHTMOST \\
\hline \hline a. But it turns out she doesn't like WHISKY & $1 !$ & \\
\hline b. But it turns out she doesn't LIKE whisky & & 1 \\
\hline c. But it turns out she DOESN'T like whisky & & 2 \\
\hline \hline
\end{tabular}

RIGHTMOST guarantees that the stress peak retracts just far enough to avoid a *STRESS-COPY violation, but no further. Candidate (c) retracts stress one word too far, making it harmonically bounded. This is indicated by the grayed-out row. Note that RIGHTMOST must be ranked below *STRESS-COPY.

Let us return to $(5 \mathrm{~b})$, repeated below, where both Deaccent Given and Deaccent Repeated fail.

a. Well, I believe we, the Americans of today, are ready to act worthy of ourselves, ready to do what must be done to ensure happiness and liberty for ourselves, our CHILDREN, and our CHILDREN's children.

(Ronald Reagan 1981)

b. Expected stress (computed by MetricalTree)

\begin{tabular}{|c|c|c|c|c|c|c|c|}
\hline & $x$ & & $x$ & & & $x$ & $x$ \\
\hline$x$ & $x$ & $x$ & $x$ & $x$ & & $x$ & $x$ \\
\hline$x$ & $x$ & $x$ & $x$ & $x$ & $x$ & $x$ & $x$ \\
\hline
\end{tabular}

c. Perceived stress (Anttila et al. 2020)

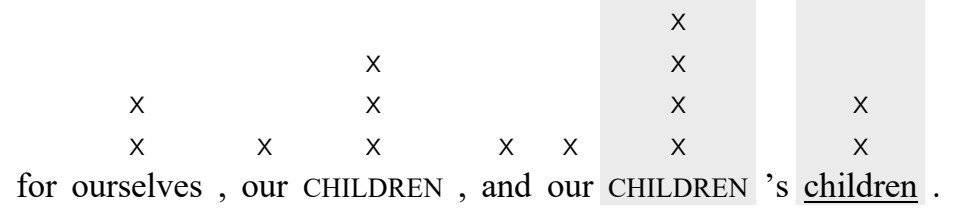

This example contains three copies of children. The expected stress contour in (12b) has a stress peak on each copy, with an extra dose of stress on the last one. The perceived stress reverses this pattern, deaccenting the last children and retracting its peak to the penultimate children, as shown in (12c). ${ }^{3}$ This is correctly predicted in (13).

Retraction in the presence of multiple copies

\begin{tabular}{|c|c|c|}
\hline \hline our CHILDREN & *STRESS-COPY & RIGHTMOST \\
\hline \hline a. and our children's CHILDREN & $2 !$ & \\
\hline b. and our CHILDREN's children & 1 & 1 \\
\hline \hline
\end{tabular}

The constraint *STRESS-COPY prefers candidate (b), where the stress peak is preceded by just one copy of children instead of two, as in candidate (a). ${ }^{4}$

In the examples we have seen so far, stress is retracted to the closest lexically stressed prosodic word on the left. In some environments, stress may land further. Consider the Radio/TV station call signs in (14). The stress peak retracts by one call letter in (14a) and by two call letters in (14b). This is borne out in (15). ${ }^{5}$

\footnotetext{
${ }^{3}$ Note that the annotator records a steadily rising stress contour ourselves ... children ... children ... up to the point of deaccentuation. This is not predicted by the MetricalTree stress algorithm, which suggests that the syntactic analysis of coordination it employs is flat, not right-branching, which yields the wrong prosody.

${ }^{4}$ Retracting stress to and would avoid all stressed copies and incorrectly win. We assume that this is ruled out because and is lexically unstressed and cannot receive phrasal stress except when focused. It is also possible that stress retraction cannot cross phrasal boundaries of sufficient strength. These issues require more exploration.

${ }^{5}$ In both cases, the stress retraction appears optional, which is not predicted by our simplified analysis.
} 
a. This is WSKG FM HD Binghamton, WSQG FM HD Ithaca, ...

(Rooth 2016:22)

b. I get ABC on channel 7 and $\mathrm{NBC}$ on channel 11 .

(Will Leben, p.c.)

Minimal stress retraction that crosses two phonological words

\begin{tabular}{|c|c|c|}
\hline \hline I get A B C on channel SEVEN and & *STRESS-COPY & RIGHTMOST \\
\hline \hline a. N B C on channel ELEVEN & $1 !$ & \\
\hline b. N B C on channel ELEVEN & 1 & 1 \\
\hline c. N B C on channel ELEVEN & & 2 \\
\hline \hline
\end{tabular}

Note that this preliminary analysis only addresses primary stress and abstracts away from degrees of stress. We will take a more fine-grained, quantitative approach to deaccentuation in Section 3.

2.2 The role of focus Many stress contours initially appear to involve Focus. Analyses of examples like (16) often assume that the stress retraction to blue reflects narrow focus on blue. Under our analysis, this assumption is unnecessary: Stress lands on blue for phonological reasons as well.

Phonology, not focus (Ladd 1980:81, pace Schwarzschild 1999:161)

\begin{tabular}{|c|c|c|}
\hline \hline $\begin{array}{l}\text { John drove Mary's red CONVERTIBLE } \\
\text { What did he drive before THAT? }\end{array}$ & *STRESS-COPY & RIGHTMOST \\
\hline \hline a. He drove her blue CONVERTIBLE & $1 !$ & \\
\hline b. He drove her BLUE convertible & & 3 \\
\hline c. He DROVE her blue convertible & 1 & 1 \\
\hline \hline
\end{tabular}

Of course, there are genuine examples where focus attracts stress, overriding normal stress (Féry \& SamekLodovici 2006, Arregi 2016, Truckenbrodt 2016). The following constraint seems inevitable:

$$
\text { FOCUS } \supset \text { STRESS } \quad \text { Focus implies stress: Assign a violation to a focused constituent }
$$
that does not contain a stress peak.

Consider the sentence People who grow rice eat rice. The phonological analysis correctly predicts that primary stress should fall on EAT. No assumptions about focus are necessary. ${ }^{6}$

Growing rice under broad focus
\begin{tabular}{|c|c|c|c|}
\hline \hline People who grow rice & FOCUS $\supset$ STRESS & *STRESS-COPY & RIGHTMOST \\
\hline \hline a. eat RICE & & $1 !$ & \\
\hline b. EAT rice & & & 1 \\
\hline \hline
\end{tabular}

Evidence for FOCUS $\supset$ STRESS comes from cases where deaccentuation is blocked:

People who grow rice eat RICE; people who grow beans eat BEANS.

Here, the phonology predicts that the second copies of rice and beans should be deaccented, but, in fact, both have stress peaks. This suggests that focus is involved, which is in line with the speaker explicitly contrasting rice and beans. The constraint FocUS $\supset$ STRESS is needed to derive the correct stress pattern. Narrow focus is indicated by the subscript Foc.

\footnotetext{
${ }^{6}$ Rooth's (1992:109) original example is People who grow rice generally only eat rice. Our simplified example suffices to make the point. For only, see below.
} 
Narrow focus blocks deaccentuation

\begin{tabular}{|c|c|c|c|}
\hline \hline People who grow rice & FOCUS $\supset$ STRESS & *STRESS-COPY & RIGHTMOST \\
\hline \hline a. eat RICEFO & & 1 & \\
\hline b. EAT rice & & & 1 \\
\hline \hline
\end{tabular}

Second Occurrence Focus presents a complication. Consider the following example (Partee 1999:215, Baumann 2016:483). We write ғоғ for First Occurrence Focus and soғ for Second Occurrence Focus.

(21) Everyone knew that Mary only eats [VEGETABLES $]_{\mathrm{FoF}}$.

If even [PAUL $]_{\mathrm{FoF}}$ knew that Mary only eats [vegetables] $]_{\mathrm{SOF}}$, then he should have suggested a different restaurant.

Let us assume that only and even are associated with focus and that focus is marked by prosodic prominence. The problem is that vegetables does not carry the expected prominence. Such "inaudible focus" implies one of two possibilities: Either focus is not necessarily marked by prosodic prominence, or only and even do not always associate with focus (see Partee 1999:215-6, Beaver et al. 2007, Büring 2015:73, Baumann 2016:484). This is a problem for views that assume a direct connection between sentence accents and meanings (e.g., Bolinger 1972). It is also a problem for our analysis as it stands. In (22), the focus-sensitive operators even and only induce narrow focus on John and juice (Büring 2015:74). The desired winner is (e), where primary stress falls on John, but unfortunately the predicted winner is (b), where juice beats John on RIGHTMOST.

Many people only drank [JUICE] $]_{\mathrm{FoF}}$ at John's party.

Even $[\mathrm{JOHN}]_{\mathrm{FOF}}$ only drank [juice $]_{\mathrm{SOF}}$ at his party.

\begin{tabular}{|c|c|c|c|}
\hline Many people only drank JUICE $E_{F \circ}$ at John's party & $\begin{array}{c}\text { FOC } \supset \\
\text { STR }\end{array}$ & *STR-C & $\begin{array}{c}\text { RIGHT- } \\
\text { MOST }\end{array}$ \\
\hline a. Even John FoF $_{\text {only drank juice }}$ SOF at his PARTY & $2 !$ & 1 & \\
\hline b. Even John $n_{\text {Fof on ly drank JUICE }}$ at his party & 1 & 1 & 3 \\
\hline c. Even John $n_{\mathrm{FoF}}$ only DRANK juice $\mathrm{SOF}_{\mathrm{f}}$ at his party & 2 & 1 & 4 \\
\hline d. Even John $n_{\mathrm{FOF}}$ ONLY drank juice ${ }_{\mathrm{SOF}}$ at his party & 2 & 1 & 5 \\
\hline e. Even JoHN $\mathbf{F O F}_{\mathrm{FF}}$ only drank juice ${ }_{\mathrm{SOF}}$ at his party & 1 & 1 & 6 \\
\hline f. EVEN John Fof $_{\text {only drank juice }}$ SOF at his party & $2 !$ & & 7 \\
\hline
\end{tabular}

This unexpected left-oriented behavior of primary stress has been observed by several authors. Féry and Samek-Lodovici (2006:141) call it innermost focus, while Büring (2015:75) derives it from a combination of his Non-Primacy Condition and Linear Condition. One possible solution is to define a specific constraint inspired by Büring's analysis that applies solely to Second Occurrence Focus:

DOMAIN Assign a violation to a Second Occurrence Focus that has a higher stress peak than a First Occurrence Focus in the same domain.

Another solution would be to assume that the second occurrence of juice rejects primary stress because the first occurrence of juice has primary stress, suggesting that we are dealing with deaccentuation: A stress peak on a repeated word is always avoided, but especially so if the antecedent itself has a stress peak. This could be stated as the phonological constraint in (25): 
The second proposal is particularly attractive because it is purely phonological and entirely general. However, both DOMAIN and *STRESS-COPY-2 derive the correct predictions in (26). We leave an empirical comparison of the two constraints for future work. For now, we state the analysis in terms of DOMAIN in (26).

\begin{tabular}{|c|c|c|c|c|}
\hline Many people only drank JUICE $E_{\mathrm{FOF}}$ at John's party & DOMAIN & $\begin{array}{c}\text { FOC } \supset \\
\text { STR }\end{array}$ & *STR-C & $\begin{array}{c}\text { RIGHT- } \\
\text { MOST }\end{array}$ \\
\hline a. Even John FoF $_{\text {only drank juice }}$ SOF at his PARTY & & $2 !$ & 1 & \\
\hline b. Even John $n_{\text {FOF }}$ only drank JUICE SOF $_{\text {Sa }}$ at his party & $1 !$ & 1 & 1 & 3 \\
\hline c. Even John FOF $_{\text {Only DRANK juice }}$ SOF at his party & & 2 & 1 & 4 \\
\hline d. Even John $n_{\mathrm{FOF}}$ ONLY drank juice SOF $_{\text {at }}$ at his party & & 2 & 1 & 5 \\
\hline 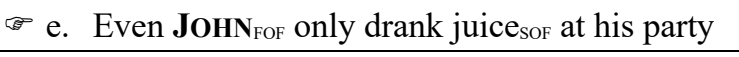 & & 1 & 1 & 6 \\
\hline f. EVEN John FoF $_{\text {only drank juice }}$ sof at his party & & $2 !$ & & 7 \\
\hline
\end{tabular}

Finally, consider a sentence with multiple segmentally identical Second Occurrence Foci. In such cases. DOMAIN is inactive and *STRESS-COPY retracts stress to the first copy. ${ }^{7}$

(27) We can't accept this: the author only cites Beaver.

Well then we know who wrote it: only BEAVER only cites Beaver.

(Beaver \& Velleman 2011:1679)

(28) Multiple segmentally identical Second Occurrence Foci

\begin{tabular}{|c|c|c|c|c|}
\hline $\begin{array}{l}\text { The author only cites BEAVERFof } \\
\text { Well then we know who WROTE it }\end{array}$ & DOMAIN & $\begin{array}{l}\text { FOC } \supset \\
\text { STR }\end{array}$ & *STR-C & $\begin{array}{l}\text { RIGHT- } \\
\text { MOST }\end{array}$ \\
\hline a. only Beaver ${ }_{\text {SOF }}$ only cites BEAVER SOF $_{\mathrm{S}}$ & & 1 & $2 !$ & \\
\hline b. only Beaver ${ }_{\mathrm{SOF}}$ only CITES Beaver ${ }_{\mathrm{SOF}}$ & & $2 !$ & 1 & 1 \\
\hline c. only Beaver ${ }_{\mathrm{SOF}}$ ONLY cites Beaver ${ }_{\mathrm{SOF}}$ & & 2 & 2 & 2 \\
\hline d. only BEAVERsof only cites Beaver ${ }_{\mathrm{SOF}}$ & & 1 & 1 & 3 \\
\hline e. ONLY Beaver ${ }_{S O F}$ only cites Beaver ${ }_{S O F}$ & & $2 !$ & 1 & 4 \\
\hline
\end{tabular}

In sum, we have outlined an analysis of a handful of cases where focus attracts stress. The interaction only works in one direction: Focus implies stress; stress does not imply focus. Stress is ultimately a mechanical phonological phenomenon with no semantic implications. What is loud is not necessarily meaningful.

2.3 Deaccentuation and pragmatics So far, we have said nothing about the examples in (4), where the deaccented words have no phonologically identical antecedent. These examples are repeated in (29):

a. Has John read Slaughterhouse-Five? No, John doesn't READ books.

(Ladd 1980:52)

b. Harry wants a VW, but his wife would prefer an AMERICAN $\underline{\text { car. }}$

(Ladd 1980:52)

While there are many possible avenues to explore, Rochemont's (2016) proposal of presupposition accommodation seems plausible. Such accommodation is illustrated by the following classic template:

John called Mary a XXX and then SHE insulted HIM.

(substitute anything for $\mathrm{XXX}$ )

Here, the entailment is not semantic, but speaker-defined (van Deemter 1994, Rochemont 2016:47): Calling someone an XXX is construed as an insult, no matter what XXX may be. We speculate that, in such cases,

${ }^{7}$ Compare this to CHILDREN'S children in (12), where the stress peak similarly falls on the first copy. 
phonology is put into productive rhetorical use. What is fundamentally a phonological alternation has acquired a semiotic function. Deaccentuation is a signal that invites the hearer to establish a similarity between two strings. Since similarity of form obviously fails (i.e., there is no segmentally identical string in the left context), the hearer pragmatically infers similarity of meaning. This interpretation pivots on shared phonological knowledge. An interesting alternative view is taken in Wagner 2012.

\section{A statistical analysis of deaccentuation}

3.1 Quantifying (de)accentuation We have defined deaccentuation as a decrease in stress relative to what is expected. On the theoretical side, we have expected stress, based on syntax and phonology; on the empirical side, we have stress as it is perceived by native speakers of English. This suggests that deaccentuation can be quantified as the difference between expected and perceived stress.

For an empirical analysis of deaccentuation, we utilize the annotated presidential corpus from Anttila et al. 2020, which includes the first inaugurals of six former U.S. presidents: Jimmy Carter, Ronald Reagan, George H. W. Bush, Bill Clinton, George W. Bush, and Barack Obama. Inaugurals are an ideal source of data for the study of deaccentuation. They are well-rehearsed and virtually disfluency-free. The speakers are emotionally involved, which expands their prosodic range and makes deaccentuation easy to hear. Finally, repetition is a rhetorical device of choice in oratorical prose. The following examples are typical of inaugurals:

(31) a. Good will begets good will.

b. Putting America back to work means putting all Americans back to work.

(George H. W. Bush 1989)

(Ronald Reagan 1981)

In the inaugural corpus, each word has two stress values: an expected ("normal") stress value computed by MetricalTree and a perceived stress value provided by an annotator. We quantify deaccentuation via an ACCENTUATION INDEX that subtracts the expected stress value from the perceived stress value for each word in a sentence, as summarized in (32).

$$
\text { Accentuation Index }=\text { Perceived Stress }- \text { Expected Stress }
$$

Since normal stress is built into the Accentuation Index, this appropriately assumes that the degree of deaccentuation may depend on syntax (Terken \& Hirschberg 1994). Moreover, this formulation has the convenience that it allows us to study both deaccentuation and the accentuation that results from stress retraction in an intuitive way: When perceived stress is less than expected stress, this results in a negative accentuation index, suggesting deaccentuation. Conversely, when perceived stress is greater than expected stress, this results in a positive index, indicating accentuation.

3.2 Statistical methods We fit linear mixed-effects regression models to the inaugural data with the Accentuation Index as the dependent variable. For interpretability, we fit separate models for nouns $(2,390$ tokens; 1,185 word types), adjectives (867 tokens; 512 word types), verbs (1,479 tokens; 914 word types), and function words $\left(3,619\right.$ tokens; 640 word types). ${ }^{8}$ In each model, we included random intercepts per president, annotator, and word type. ${ }^{9}$ We used the statistical computing language $\mathrm{R}$ (version 3.6.2; R Core Team, 2013) and the lme4 (Bates et al. 2015) and lmerTest (Kuznetsova et al. 2017) packages to fit and interpret the regression models.

To test the validity of *STRESS-COPY, we included a REPETITION variable as a continuous fixed effect. Each word was labeled with its distance in words from its nearest string identical antecedent. In the case of adjacent identical words, the righthand word had a Repetition value of 1; distances that exceeded 100 were

\footnotetext{
${ }^{8}$ Lexical categories were based on universal part-of-speech (UPOS) tags assigned by Stanza (Peng et al. 2020); nouns included any words tagged with NOUN, adjectives with ADJ, verbs with VERB, and function words with ADP, DET, CCONJ, SCONJ, or PART.

${ }_{9}$ We dropped the random effect for word type in the adjectives model, due to the high type-token ratio (0.59) of adjectives across the six addresses, which led to "singular fit" issues.
} 
squashed to 100, and words that did not have antecedents were similarly assigned a Repetition value of 100 . Note that we decided to include repetition as a measure of distance, rather than as a binary variable (i.e., marking the presence or absence of an identical antecedent). This was done for two reasons. First, we do not know a priori to what domain, if any, deaccentuation is limited. For instance, in examples (2) and (9), we see that a word will deaccent even if its identical antecedent does not appear within the same clause. Second, from a language processing standpoint, we suspect that deaccentuation will exhibit "decay" effects, such that a word is both more likely to deaccent the closer it is to its antecedent and that this deaccentuation will be more pronounced with smaller distances.

Since the mechanics of RightMOST is inherent to the Nuclear Stress Rule, which informs our expected stress values and, by extension, the Accentuation Index, we refrained from including a fixed effect that directly parallels this constraint. Instead, we evaluated the accentuation that, by hypothesis, would result from stress retraction. We did this by including an additional distance variable, called RETRACTION, as a fixed effect: We identified the rightmost content word (henceforth, the retraction site) that precedes a repeated word within the same sentence and assigned it the repeated word's Repetition value, as illustrated in Figure 1. This was done to allow the strength of the deaccentuation on the repeated word to mediate the strength of accentuation on the retraction site. Mirroring Repetition, we converted any Retraction value that exceeded 100 to 100 and assigned a Retraction value of 100 to any word that was not a retraction site.

$\begin{array}{llll}\text { Rep }=100 & \text { Rep }=100 & \text { Rep }=2 \\ \text { Ret }=100 & \text { Ret }=2 & \text { Ret }=100 \\ & & & \\ & & & \\ \text { <corpus }>\text { Goodwill } & \text { begets } & \text { Go } & \text { goodwill }_{R W} \cdot</ \text { corpus }>\end{array}$

Figure 1. Annotating Repetition and Retraction values for a sentence adapted from George H. W. Bush's 1989 inaugural address. Repetition (Rep) is the distance between a Repeated Word $(R W)$ and its Antecedent $(A)$, which is labeled on the Repeated Word. The intervening Retraction Site $(R S)$ is assigned a Retraction $(R e t)$ value that is equal to the Repeated Word's Rep value. Rep equals 100 if a word does not have an antecedent and Ret equals 100 if a word does not serve as a retraction site under our hypothesis. In this toy example, we pretend no words precede or follow the sentence.

The fact that the Accentuation Index is a continuous metric allows us to accommodate any imperfections in MetricalTree's algorithm, as we are more interested in which directions Repetition and Retraction "tug" at this response variable. We hypothesized that smaller Repetition values would lead to greater deaccentuation (i.e., a positive regression coefficient), whereas smaller Retraction values would lead to greater accentuation (i.e., a negative regression coefficient). Since we assume that differences between smaller distances are more meaningful than differences between larger distances, we log-transformed both the Repetition and Retraction variables. Before calculating the Accentuation Index, we also normalized the perceived and expected stress values by the maximum perceived and expected stress peaks, respectively, for each sentence.

3.3 Results and analysis We tested the effects of Repetition and Retraction on the Accentuation Index to evaluate the phonological analysis outlined in Section 2.1. Across the board, we found that Repetition was significantly associated with accentuation indices (nouns: $\mathrm{p}<0.001$; adjectives: $\mathrm{p}<0.001$, verbs: $\mathrm{p}<0.001$; function words: $\mathrm{p}=0.011$ ), such that smaller distances between identical words predicted greater deaccentuation on the righthand occurrences. For nouns and verbs, we further found that smaller Retraction values predicted greater accentuation ( $\mathrm{p}<0.001$ for both); this effect was also marginally non-significant for adjectives $(\mathrm{p}=0.065)$. Since we limited retraction sites to content words in our formulation, we did not include Retraction as a fixed effect in the function word model. Our results are summarized in Table 1.

The fact that repetition drives deaccentuation across nouns, adjectives, verbs, and function words lends support to the *STRESS-COPY constraint. It provides evidence for the hypothesis that deaccentuation is a general, postlexical phonological rule of English that applies to all lexical categories. This finding contrasts with studies that tether deaccentuation to givenness or information status (e.g., van Deemter 1994, 


\begin{tabular}{lccr}
\hline Fixed effects & Estimate & SE & p-value \\
\hline Nouns & & & \\
$\quad$ Repetition & $3.34 \times 10^{-2}$ & $5.56 \times 10^{-3}$ & $<0.001$ \\
$\quad$ Retraction & $-4.84 \times 10^{-2}$ & $5.62 \times 10^{-3}$ & $<0.001$ \\
Adjectives & & & \\
$\quad$ Repetition & $9.96 \times 10^{-2}$ & $8.98 \times 10^{-3}$ & $<0.001$ \\
$\quad$ Retraction & $-2.47 \times 10^{-2}$ & $1.34 \times 10^{-2}$ & 0.065 \\
Verbs & & & \\
$\quad$ Repetition & $4.68 \times 10^{-2}$ & $8.08 \times 10^{-3}$ & $<0.001$ \\
$\quad$ Retraction & $-3.28 \times 10^{-2}$ & $8.40 \times 10^{-3}$ & $<0.001$ \\
Function words & & & \\
$\quad$ Repetition & $6.97 \times 10^{-3}$ & $2.75 \times 10^{-3}$ & 0.011 \\
\hline$\quad$ Table 1. Associtions
\end{tabular}

Table 1. Associations with the Accentuation Index.

Schwarzschild 1999). As Nenkova et al. (2007:13) note, "[T] he information status distinction applies only to referring expressions and has undefined values for words such as verbs, adjectives or function words". Our findings highlight a key difference between Deaccent Given and Deaccent Repeated: All words exhibit repetition-driven destressing, not just referring expressions.

Our results further suggest that deaccentuation indeed co-occurs with the accentuation of the nearest leftward content word, as proposed in our phonological analysis. In particular, the negative Retraction coefficients show that nouns and verbs (and perhaps adjectives) serve as retraction sites, such that they become accented when they are the nearest content word to precede a word with an identical antecedent; the closer the repeated word is to its antecedent, the stronger the accentuation on the intervening retraction site.

Finally, we note the small effect sizes in Table 1, especially for function words. These effect sizes are reasonable when we recall that the Accentuation Index operates on normalized values of perceived and expected stress. Thus, its range is -1 to 1 . That the Repetition effect size is tiniest for function words is intuitive: Function words are typically assigned less stress than content words, and therefore present less room to deaccent.

\section{Summary}

Our proposal can be summarized as follows:

a. Deaccentuation is a phonological rule of English.

b. Deaccentuation means to be perceived with less stress than expected.

c. Deaccentuation is stress retraction that results in a culminative and hierarchical stress contour.

d. Deaccentuation displays "decay" effects, suggesting that processing matters.

Our analysis is built on the assumption that stress is fundamentally a mechanical phenomenon grounded in syntax and phonology (Chomsky \& Halle 1968). Understanding deaccentuation requires an understanding of these mechanical aspects of stress. We used MetricalTree (Anttila et al. 2020) to compute the loci and degrees of expected stress in a corpus and used the result to detect deaccentuation-words that are perceived as having less stress than expected. Deaccentuation is part of the phonological system of English. It cannot be detected directly from acoustics or from perceived prominence alone. Expectations matter and they depend on syntax and phonology. It is our hope that, with an explicit phonological theory of expected phrasal stress in place, we are in a better position to explore the semantics and pragmatics of deaccentuation.

\section{References}

Anttila, Arto, Timothy Dozat, Daniel Galbraith, and Naomi Shapiro. 2020. Sentence stress in presidential speeches. In Gerrit Kentner and Joost Kremers (eds.), Prosody in Syntactic Encoding, Berlin/Boston: Walter De Gruyter, 17-50. 
Arnold, Jennifer and Duane Watson. 2015. Synthesising meaning and processing approaches to prosody: Performance matters. Language, Cognition and Neuroscience, 30(1-2), 88-102.

Arregi, Karlos. 2016. Focus projection theories. In Caroline Féry and Shinichiro Ishihara (Eds.), The Oxford Handbook of Information Structure, Oxford: Oxford University Press, 185-202.

Artstein, Ron. 2004. Focus below the word level. Natural Language Semantics 12(1), 1-22.

Bates, Douglas, Martin Maechler, Ben Bolker, Steve Walker. 2015. Fitting Linear Mixed-Effects Models Using lme4. Journal of Statistical Software 67(1), 1-48.

Baumann, Stefan. 2016. Second occurrence focus. In Caroline Féry and Shinichiro Ishihara (Eds.), The Oxford Handbook of Information Structure, Oxford: Oxford University Press, 483-502.

Beaver, David I., Brady Clark, Edward S. Flemming, T. Florian Jaeger, and Maria Wolters. 2007. When semantics meets phonetics: Acoustical studies of second-occurrence focus. Language 83(2), 245-276.

Beaver, David, and Dan Velleman. 2011. The communicative significance of primary and secondary accents. Lingua 121(11), 1671-1692.

Bolinger, Dwight. 1972. Accent is predictable (if you are a mind reader), Language 48, 633-644.

Büring, Daniel. 2015. A theory of second occurrence focus. Language, Cognition and Neuroscience, 30(1-2), 73-87.

Chomsky, Noam, and Morris Halle. 1968. The Sound Pattern of English. New York: Harper and Row.

Cinque, Guglielmo. 1993. A null theory of phrase and compound stress. Linguistic Inquiry 24, 239-298.

van Deemter, Kees. 1994. What's new? A semantic perspective on sentence accent. Journal of Semantics 11, 1-31.

Féry, Caroline, and Vieri Samek-Lodovici. 2006. Focus projection and prosodic prominence in nested foci. Language 82(1), 131-150.

Gussenhoven, Carlos. 2004. The Phonology of Tone and Intonation, Cambridge: Cambridge University Press.

Gussenhoven, Carlos. 2011. Sentential prominence in English. In Marc van Oostendorp, Colin J. Ewen, Elizabeth Hume \& Keren Rice (eds.), The Blackwell Companion to Phonology, Vol. 2. Malden, MA: Wiley-Blackwell, 2778-2806.

Klassen, Jeffrey and Michael Wagner. 2017. Prosodic prominence shifts are anaphoric. Journal of Memory and Language 92, 305-326.

Kuznetsova, Alexandra, Per B. Brockhoff, and Rune H. B. Christensen. 2017. lmerTest Package:vTests in Linear Mixed Effects Models. Journal of Statistical Software, 82(13), 1-26. https://doi.org/10.18637/jss.v082.i13.

Ladd, D. Robert. 1980. The Structure of Intonational Meaning. Bloomington \& London: Indiana University Press.

Ladd, D. Robert. 1996. Intonational Phonology. Cambridge: Cambridge University Press.

Liberman, Mark. 1975. The Intonational System of English. Ph.D. thesis, Massachusetts Institute of Technology. Published in 1979 by Garland Publishing, New York \& London.

Liberman, Mark and Alan Prince. 1977. On stress and linguistic rhythm. Linguistic Inquiry 8(2), 249-336.

Nenkova, Ani, Jason Brenier, Anubha Kothari, Sasha Calhoun, Laura Whitton, David Beaver \& Dan Jurafsky. 2007. To memorize or to predict: Prominence labeling in conversational speech. Proceedings of the North American Chapter of the Association for Computational Linguistics: Human Language Technologies, 9-16. http://www.aclweb.org/anthology/N07-1002.

Partee, Barbara H. 1999. Focus, Quantification, and Semantics-Pragmatics Issues. In Peter Bosch and Rob van der Sandt (Eds.), Focus: Linguistic, Cognitive, and Computational perspectives. Cambridge: Cambridge University Press, 213-231.

Prince, Alan. 1983. Relating to the grid. Linguistic Inquiry 14(1). 19-100.

Rochemont, Michael. 2016. Givenness. In Caroline Féry and Shinichiro Ishihara (Eds.), The Oxford Handbook of Information Structure, Oxford: Oxford University Press. 41-63

R Core Team. 2013. R: A language and environment for statistical computing. https://www.r-project.org/

Rooth, Mats. 1992. A theory of focus interpretation. Natural Language Semantics 1(1), 75-116.

Rooth, Mats. 2016. Alternative semantics. In Caroline Féry and Shinichiro Ishihara (Eds.), The Oxford Handbook of Information Structure, Oxford: Oxford University Press, 19-40.

Schwarzschild, Roger. 1999. GIVENness, AvoidF and other constraints on the placement of accent. Natural Language Semantics 7(2), 141-177.

Terken, Jacques and Julia Hirschberg. 1994. Deaccentuation of words representing 'given' information: Effects of persistence of grammatical function and surface position. Language and Speech 37(2), 185-145.

Truckenbrodt, Hubert. 2016. Focus, intonation, and tonal height. In Caroline Féry and Shinichiro Ishihara (Eds.), The Oxford Handbook of Information Structure, Oxford: Oxford University Press, 463-482.

Wagner, Michael. 2012. A givenness illusion. Language and Cognitive Processes, 27(10), 1433-1458.

Wagner, Michael. 2020. Prosodic Focus. In D. Gutzmann, L. Matthewson, C. Meier, H. Rullmann, and T. E. Zimmermann (eds.), The Wiley Blackwell Companion to Semantics. Wiley-Blackwell.

Wagner, Michael, and Katherine McCurdy. 2010. Poetic rhyme reflects cross-linguistic differences in information structure. Cognition 117(2), 166-175.

Williams, Edwin. 1997. Blocking and Anaphora. Linguistic Inquiry 28(4), 577-628. 